\title{
Diagnostic Accuracy of Magnetic Resonance Spectroscopy (MRS) in Diagnosing Malignant Breast Lesions Taking Histopathology as Gold Standard
}

\author{
ADNAN AHMED ${ }^{1}$, JAWAD ALI MEMON², MUHAMMAD SIBTAIN SHAH ${ }^{3}$, HAFEEZ UR REHMAN ${ }^{4}$, TAHIR BAIG ${ }^{5}$, \\ MUHAMMAD NAUMAN AKRAM ${ }^{6}$ \\ ${ }^{1}$ Associate Professor, Radiology, Liaquat University of Medical and Health Sciences, Jamshoro \\ ${ }^{2}$ Assistant Professor Radiology People's University of Medical and Health Sciences for Women, Nawabshah \\ ${ }^{3}$ Assistant Professor Oncology Peoples University of Medical \& Health Sciences for Women Nawabshah \\ ${ }^{4}$ Senior Registrar Radiology, Gajju Khan Medical College, Swabi \\ ${ }^{5}$ Assistant Professor Radiology, Rai Medical College, Sargodha \\ ${ }^{6}$ Assistant Professor Radiology, Sahara Medical College, Narowal \\ Corresponding author: Dr Adnan Ahmed, Email: dradnanqureshi@hotmail.com, Cell No. +923003067950
}

\begin{abstract}
ABSTARCT
Background and Aims: Breast cancer is the prime cause of mortality among women of both developing and developed world. Out of $34.6 \%$ of female cancer patients, malignant breast cancer being the most common cancer found in Pakistan. The current study aims to evaluate the diagnostic accuracy of magnetic resonance spectroscopy in diagnosing malignant breast lesions taking histopathology as a gold standard.

Materials and Methods: This cross-sectional study was carried out on 135 female patients with suspicious palpable lesions for malignancy referred from surgical OPD of Liaquat University of Medical and Health Sciences, Jamshoro during the period from October 2020 to March 2021. Magnetic resonance spectroscopy (MRS) dynamic enhanced images taken with contrast on 1.5 Tesla MRI machines were assessed based on kinetic and morphology. Malignancy biomarker was assessed with choline peak (Cho) allowed by MRS. The Single-voxel technique was utilized in order to evaluate the diagnostic performance of MRS in breast lesions malignancy. A comparison was made between MRS and biopsy findings.

Results: Out of 135 female patients, 118 (87.40\%) were malignant lesions patients assessed by MRS while histopathologically proven patients were $104(77.33 \%)$. The calculated mean age of all the malignant patients was $48.3 \pm 14.5$ years with a range of 40-79 years. The diagnostic parameters of MRS such as specificity, accuracy, sensitivity, negative predictive value (NPV), and positive predictive value (PPV) was $74 \%, 88.2 \%, 93 \%$, $77.8 \%$, and $93.1 \%$ respectively while taking histopathology as a gold standard.

Conclusion: MRS must be utilized as a primary imaging technique for the diagnosis of breast lesions malignancy due to its higher specificity, sensitivity, and accuracy in breast lumps characterization. MRS was found to be specific $74 \%$, sensitive $88.2 \%$, and accurate $93 \%$ in malignant breast cancer diagnosis.

Keywords: MRS, Malignant breast lesions, Histopathology
\end{abstract}

\section{INTRODUCTION}

Breast cancer is the prime cause of mortality among female patients in both developing and developed worlds. The prevalence of breast cancer incident rate was found higher $(80 / 100000)$ in developed regions as compared to developing regions (40/100000) [1]. About $35 \%$ of female cancers account for the commonest malignancy in the breast [2] and almost 89000 women per annum suffer from it [3]. MRS core biopsy diagnosis is an effective and efficient breast lesion as compared to the surgical biopsy based on cost, less invasive, and convenience. Pathologic reports found $75 \%$ of benign cases assessed by biopsy due to patient's reluctance to biopsy subjected [1-4]. A reliable and invasive approach is an effective diagnosis and need of the hour for breast lesions suspicious [5].

MRS is a part of triple assessment radiological techniques used for malignant breast lesions taking histopathology as a gold standard. MRS detects earlystage breast cancer as a primary imaging technique. However, its specificity and sensitivity varies from $82-98 \%$ and $68-88 \%$ respectively [6]. MRS detects malignant breast cancer with higher sensitivity. However, discrepancies were found in MRS accuracy and sensitivity as it gives more sensitive and specific results compared to other radiological techniques $[7,8]$. One study conducted in 2012 found specificity and sensitivity of MRS were 68\% and $71 \%$ respectively [9]. Better visual inspection and spatial information by the three-dimensional ability of MRS could be provided by MRS. Post-surgical changes such as neo-adjuvant therapy assessment and integrity of breast implant were assessed by MRS role [10-12]. Breast MRS differentiate the normal breast from lesions based on lesions permeability and vascular differences [13]. Lesions enhancement patterns, distribution, size, kinetic curve description, margins with initial peaks and contrast enhancement delayed phases were described by MRS [14].

Many researchers studied the diagnostic accuracy of $M R I$ in the diagnosis of malignant breast cancer. But very few investigations have been carried out on MRS diagnosis of breast lesions. Keeping in view the lack of enough data and previous studies confliction in Pakistan, the current study aims to determine the diagnostic accuracy of MRS in the diagnosis of malignant breast lesions taking histopathology as a gold standard. 


\section{MATERIALS AND METHODS}

This cross-sectional study was carried out in the department of Radiology at Liaquat University of Medical and Health Sciences, Jamshoro. A total of 135 female patients were registered as they met the inclusion criteria. These patients had either suspicious breast lesions or malignant referrals from surgical OPD with breast lumps. Patients with malignant lesions and who had chemotherapy or underwent surgery were excluded. Out of 135 female patients, $118(87.40 \%)$ were malignant lesions patients assessed by MRS while histopathologically proven patients were 104 (77.33\%). MRS and histopathology analysis was compared in the preoperative biopsy. Magnetic resonance spectroscopy (MRS) dynamic enhanced images taken with contrast on 1.5 Tesla MRI machines were assessed based on kinetic and morphology. Malignancy biomarker was assessed with choline peak (Cho) allowed by MRS. The Single-voxel technique was utilized in order to evaluate the diagnostic performance of MRS in breast lesions malignancy.

A double breast coil with gentle compression application on both breasts was utilized to scan all the patients in order to mitigate the effects of patient motion in the prone position. Contrast injection could be optimized with a three-way stopcock on 20-22 canola gauges to secure the intervention line before adjusting the position. Multi-planar reconstruction with thin slices generated was employed through MIP (maximum intensity projection) three-dimensional for fat suppression and subtraction. Contrast injection was injected in order to perform scanning after 20 seconds while another intravenous dose was injected with $0.2 \mathrm{ml}$ per $\mathrm{kg}$ and saline of $20 \mathrm{ml}$ flush for contrast-enhanced images by MRS. Dynamically, four postcontrast scans took 7 minutes 35 seconds duration for the complete sequence. Kinetic curve types II and III demonstration with spiculated borders and ductal pattern or peripheral rim were used for malignancy diagnosis on MRS.

Statistical Analysis: Data analysis was carried out using SPSS version 20. Frequency and percentage were calculated for malignant breast lesions based on their kinetic features and morphology. The comparison was made with histopathology findings and MRS diagnosis parameters such as specificity, accuracy, sensitivity, NPV, and PPV were calculated.

\section{RESULTS}

Out of 135 female patients, $118(87.40 \%)$ were malignant lesions patients assessed by MRS while histopathologically proven patients were 104 (77.33\%). The calculated mean age of all the malignant patients was $48.3 \pm 14.5$ years with a range of 42-59 years. The diagnostic parameters of MRS such as specificity, accuracy, sensitivity, negative predictive value (NPV), and positive predictive value (PPV) was $74 \%$, $88.2 \%, 93 \%, 77.8 \%$, and $93.1 \%$ respectively while taking histopathology as a gold standard. The age-wise distribution was done for 135 patients enrolled in this study. In group I, maximum patients fall between $42-59$ years and the average mean age was $48.3 \pm 14.5$ years. Out of 118 malignant lesions patients, ductal enhancement was 67 $(59.3 \%)$ and peripheral enhancement 41 (40.7\%) as shown in Table I and Figure I. type I curve, type II plateau curve and type III washout curve was seen in 17 (12.5\%), 32 (23.7) and 86 (63.7) respectively. MRS diagnostic parameters such as specificity, sensitivity, accuracy, negative predictive value, and positive predictive value were reported $74 \%, 88.2 \%, 83 \%, 77.8 \%$, and $93.1 \%$ as shown in Table II and Figure II.

Table I. Frequency of MRS morphology features

\begin{tabular}{|l|l|l|}
\hline MRS Parameters & $\begin{array}{l}\text { Frequency } \\
(\mathrm{n})\end{array}$ & $\begin{array}{l}\text { Percentage } \\
(\%)\end{array}$ \\
\hline Regular borders, no enhancement & 12 & 9 \\
\hline $\begin{array}{l}\text { Regular borders, homogenous } \\
\text { enhancement }\end{array}$ & 15 & 11.1 \\
\hline $\begin{array}{l}\text { Speculated borders, peripheral } \\
\text { enhancement }\end{array}$ & 41 & 30.3 \\
\hline $\begin{array}{l}\text { Speculated borders, ductal } \\
\text { enhancement }\end{array}$ & 67 & 49.6 \\
\hline Total & & \\
\hline
\end{tabular}

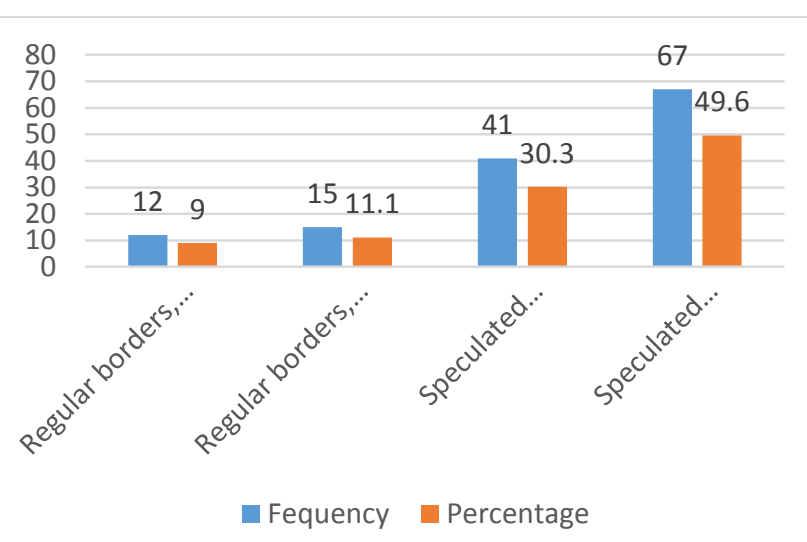

Figure I. Frequency of MRS morphology features

Table II. MRS and histopathology findings of Breast Lesions

\begin{tabular}{|l|l|}
\hline MRS findings & Histopathology Findings n (\%) \\
\hline Malignant (+ve) & $118(87.40)$ \\
\hline Specificity & $74 \%$ \\
\hline Sensitivity & $88.2 \%$ \\
\hline Accuracy & $83 \%$ \\
\hline NPV & $77.8 \%$, \\
\hline PPV & $93.1 \%$ \\
\hline
\end{tabular}

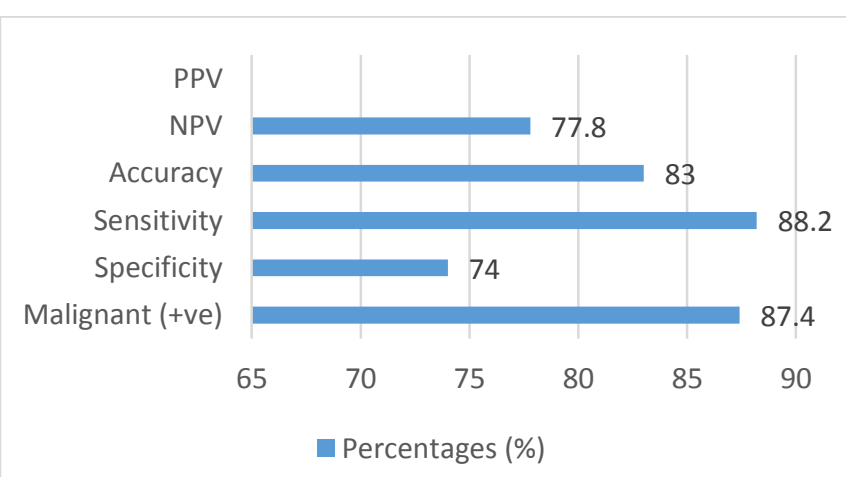

Figure II. MRS and histopathology findings of Breast Lesions

\section{DISCUSSION}

Pakistan is being ranked 2nd in Asia in regard to the number of breast cancer cases reported worldwide. Breast 
cancer can be diagnosed with multimodality and radiological techniques for imaging. MRS is the preferred radiological assessment technique used for breast lesions detection and identification due to the higher accuracy and increased performance in dense breast compared to the conventional mammography which has limitations [15]. MRS of breast is a popular trend in imaging tools used in radiology. Breast lesions functional and structural details were provided based on vascular characteristics [16]. Speculated borders of malignant lesions with peripheral/ductal enhancement [17] and kinetic curve of type III [18].

In our study, MRS identified and detected118 cases of malignant lesions among a total of 135 female patients while 104 patients were confirmed by histopathology findings. Out of118 malignant lesions patients, ductal enhancement was 67 (59.3\%) and peripheral enhancement $41(40.7 \%)$ as shown in Table I and Figure I. type I curve, type II plateau curve, and type III washout curve was seen in 17 (12.5\%),32 (23.7) and 86 (63.7) respectively. MRS diagnostic accuracy has been found different in different studies with a sensitivity of 95\% [19] and 71.7\% [20]. Specificity variations were $75 \%$ and $68 \%$. Another study found MRS sensitivity, specificity, NPV, and PPV in order of $94 \%, 85 \%, 90 \%$ and $82 \%$ respectively with an overall accuracy of $90 \%$ [21]. The p-value of $<0.001$ was considered a significant value. Malignant breast lesions diagnosis was found to have an overall diagnostic accuracy of about $89.3 \%$. MRS recommendation in preoperative characteristics disease and high-level diagnostic accuracy was calculated on statistical analysis.

Our study had limitations such as contrast material, high-cost investigation, prone position and scan time, and patient less comfort ability and suspicious lumps patients' referral, more patients were having malignant breast lesions. The study population was single-centered based on patients and found biased. Breast cancer modality in patients and judicious patterns were interpreted by the results.

\section{CONCLSIONS}

MRS is the prime imaging modality for breast lesions proper characterization. MRS gives higher sensitivity, specificity, and overall diagnostic accuracy in breast lesions diagnosis compared to other radiological modalities. MRS was found to be specific $74 \%$, accurate $88.2 \%$, and sensitive $93 \%$ in malignant breast cancer diagnosis.

\section{REFERENCES}

1. Mann RM, Kuhl CK, Moy L. Contrast-enhanced MRI for breast cancerscreening. J MagnReson Imaging. 2019;50(2):377-390.5. Lee JM, Ichikawa L, Valencia E, et al. Performance benchmarksfor screening breast MR imaging in community practice. Radiology.2017;285(1):44-52

2. Ahmadani MA, Bhatty S, ulAbideen Z, Yaseen MS, Laique T, Malik J. Imaging in Breast Cancer: Use of Magnetic Resonance Spectroscopy. Cureus. 2020 Aug;12(8).

3. Jia C, Li Z, Guo D, Zhang Z, Yu J, Jiang G, Xing X, Ji S, Jin $F$. Brain Metastases of Non-Small Cell Lung Cancer: Magnetic Resonance Spectroscopy for Clinical Outcome Assessment in Patients with Stereotactic Radiotherapy. OncoTargets and therapy. 2020;13:13087.
4. Shaukat U, Ismail M, Mehmood N. Epidemiology, major risk factors and genetic predisposition for breast cancer in the Pakistani population. Asian Pac J Cancer Prev 2013; 14:5625-9. 3.

5. Asif HM, Sultana S, Akhtar N, Rehman JU, Rehman RU. Prevalence, risk factors and disease knowledge of breast cancer in Pakistan. Asian Pac J Cancer Prev 2014; 15:44116. 4.

6. Park HS, Decker RH, Wilson LD, Yu JB. Prophylactic cranial irradiation for patients with locally advanced non-small-cell lung cancer at high risk for brain metastases. Clin Lung Cancer. 2015;16(4):292-297. doi:10.1016/j.cllc.2014.11.005

7. Takhellambam YS, Lourembam SS, Sapam OS, Kshetrimayum RS, Ningthoujam BS, Khan T: Comparison of ultrasonography and fine needle aspiration cytology in the diagnosis of malignant breast lesions. J ClinDiagn Res. 2013, 7:2847-2850. 10.7860/JCDR/2013/6493.3887

8. Razek AA, Abdalla A, Ezzat A et al (2014) Minimal hepatic encephalopathy in children with liver cirrhosis: diffusionweighted MR imaging and proton MR spectroscopy of the brain. Neuroradiology 56:885-891

9. Sepahdari AR, Politi LS, Aakalu VK et al (2014) Diffusionweighted imaging of orbital masses: multi-institutional data support a 2-ADC threshold model to categorize lesions as benign, malignant, or indeterminate. AJNR Am J Neuroradiol 35:170-175

10. Hu Q, Liu S. Progresses of Functional Magnetic Resonance Imaging Diagnosis in Breast Cancer. Yangtze Medicine. 2020 Jun 29;4(02):85.

11. Seifeldein G, Elsaba TM, Gabr A, Mohamed DO, Elmorshidy $\mathrm{S}$, Atta $\mathrm{H}$. The diagnostic efficacy of tailored multiparametric breast MRI in indeterminate mammographic lesions: A single tertiary oncology center. International Journal of Cancer and Biomedical Research. 2020 Dec 1;4(3):217-28.

12. Kouskoumvekakil, Panagiotou G. Navigating the human metabolomefor biomarker identification and design of pharmaceutical molecules.J Biomed Biotechnol. 2011; 2011:525497.

13. Silva C, Perestrelo R, Silva P, Tomás H, Câmara JS. Breast cancermetabolomics: from analytical platforms to multivariate data analy-sis. A Review. Metabolites. 2019;9(5):102.

14. Yang L, Wang Y, Cai H, Wang S, Shen Y, Ke C. Application ofmetabolomics in the diagnosis of breast cancer: a systematic review.J Cancer. 2020;11(9):2540-2551.

15. Romero-Garcia S, Lopez-Gonzalez JS, Báez-Viveros JL, Aguilar-Cazares D, Prado-Garcia H. Tumor cell metabolism: an integral view.CancerBiolTher. 2011;12(11):939-948.

16. More TH, RoyChoudhury S, Christie J, et al. Metabolomicalterationsininvasiveductal carcinoma of breast: a comprehensive metabolomicstudy using tissue and serum samples. Oncotarget. 2017;9(2):2678-2696.

17. Park J, Shin Y, Kim TH, Kim DH, Lee A. Plasma metabolitesas possible biomarkers for diagnosis of breast cancer. PLoS One.2019;14(12):e0225129.

18. Eghlimi R, Shi X, Hrovat J, Xi B, Gu H. Triple negative breast can-cer detection using LC-MS/MS lipidomic profiling. JProteomeRes.2020;19(6):2367-2378

19. Kneeshaw PJ, Turnbull LW, Drew PJ. Current applications and future direction of MR mammography. $\mathrm{Br} \mathrm{J}$ Cancer 2003; 88: 4-10.

20. Shafqat G, Agha A, Masror I, Rehan M, Afzal S. Dynamic contrast enhanced MRI breast for lesion detection and characterization with histopathological correlation: Preliminary experience at tertiary care hospital. J Pak Med Assoc 2011; 61:252. 